\title{
Current status of the programs for detection of hearing loss in children younger than six months in Cali
}

\section{Estado actual de los programas de detección de pérdidas auditivas en niños menores de seis meses en Cali}

\author{
Laura González, SPc ${ }^{1}$, Julia María Fernández de Soto, SPc ${ }^{1}$, Martha Inés Torres, MSc ${ }^{2}$
}

\section{Summary}

Background: Data is scarce in Colombia when dealing with the current circumstances of programs for detecting hearing loss in children younger than six months and, therefore, statistical data is limited on congenital or earlyacquired deafness. Studies have been conducted in the country on detection and prevention of hearing problems in the healthcare institutions in Antioquia, Quindío, Cauca, Valle, and Risaralda. All these studies were carried out between 1993 and 1995 and included children older than one year of age, which shows evidence of the lack of knowledge about the importance of early detection in the hearing-communicative health of children.

Objective: To identify the current procedures and protocols to detect hearing loss in children younger than six months in Cali through a descriptive research in different healthcare institutions of the city.

Methods: A descriptive study was carried out with a population of 722 private, public and/or mixed Health Service Providing Institutions from the city of Cali, registered in the database of the Department of Health of Valle del Cauca, Colombia in February 2007. A list was filled out to determine which of these institutions had services like delivery room and/or growth-development programs and/or audiology services and it was found that these aspects were met in 151 institutions that constituted the research sample. Thereafter, a survey was applied in these institutions to identify the procedures utilized for hearing loss detection, the health professionals that carry this out, and the follow up and the speech-language treatment performed to the children detected.

Results: $95 \%$ of the healthcare institutions surveyed (144 institutions) do not perform procedures to detect hearing loss in children younger than six months. Only six of the private-sector institutions in Cali performed such procedures. The procedures used by these six institutions are all performed with equipment and protocols for objective tests.

Conclusions: No public entity in the city of Cali has programs for early detection of hearing loss. It is necessary to implement strategies to train institutions, and associations of government institutions involved in healthcare, so that they can apply programs of universal hearing screening for neonates, while they disseminate such programs at regional and national levels.

Keywords: Hearing screening; Newborn hearing loss; Detection programs.

Colomb Med. 2012; 43: 73-81

\section{Resumen}

Antecedentes: Son escasos los datos en Colombia acerca del estado actual de los programas de detección de pérdidas auditivas y por ende escasa la información estadística de la sordera congénita o tempranamente adquirida. En el país se realizaron estudios entre 1993 y 1995 con población infantil mayor de un año sobre detección y prevención

1 Professor, School of Human Rehab, Faculty of Health, Universidad del Valle, Cali, Colombia. e-mail: lagonsa5@hotmail.com juliafesa@cable.net.co

2 Professor, Universidad Santiago de Cali, Cali, Colombia. e-mail: martha.torres0410@hotmail.com

Received for publication May 9, 2011 Accepted for publication August 10, 2011 
de problemas auditivos en los servicios seccionales de salud de Antioquia, Quindío, Cauca, Valle y Risaralda. Este panorama refleja que existe cierto desconocimiento sobre la importancia de la detección temprana para la salud auditiva-comunicativa de la infancia.

Objetivo: Identificar el estado actual de los procedimientos y protocolos de detección de pérdidas auditivas en niños menores de seis meses en Cali, mediante una investigación de tipo descriptivo en diferentes instituciones de la ciudad.

Métodos: Se realizó un estudio descriptivo con una población universo conformada por 722 instituciones prestadoras de salud (IPS) de Cali privadas, estatales y/o mixtas, registradas a febrero de 2007 en la base de datos de la Secretaría de Salud Departamental del Valle del Cauca. Se diligenció una ficha de inclusión para determinar cuáles de estas IPS tenían servicios de sala de partos y/o crecimiento y desarrollo y/o audiología y se encontró que estos aspectos se cumplían en 151 instituciones que se constituyeron en la muestra del estudio. Luego, se aplicó una encuesta en estas instituciones para identificar los procedimientos utilizados para la detección de pérdidas auditivas, los profesionales de salud que los llevaban a cabo y el seguimiento y tratamiento fonoaudiológico realizados a los niños detectados.

Resultados: Del total de las IPS encuestadas, 95\% (144 instituciones) no realiza procedimientos de detección de pérdidas auditivas en niños menores de seis meses de edad. Sólo seis instituciones de tipo privado de Cali los ejecutan con equipos y protocolos para pruebas objetivas.

Conclusiones: Ninguna entidad pública de la ciudad de Cali tiene programas de detección temprana de hipoacusias. Es necesario implementar estrategias para capacitar a instituciones, asociaciones y estamentos gubernamentales del sector salud, para la aplicación y difusión del programa de tamizaje auditivo universal para neonatos a niveles regional y nacional.

Palabras claves: Tamizaje auditivo; Hipoacusia en neonatos; Programas de detección.

Colomb Med. 2012; 43: 73-81

Lack of evaluation and early intervention of hearing problems causes late development of the auditorycommunicative abilities of the child. The first three years of the child's life are the most critical in terms of language development. If children are not exposed to auditory, linguistic, and social stimulation, their emotional and social development could be severely affected $^{1-3}$.

If we implement appropriate early measures within the child's first three months, we can avoid delays in oral language development caused by hearing loss. The first of these measures is the early detection of hearing disorders through an evaluation, which allows identifying children who do not normally react to acoustic stimuli. Once identified, they require close follow up for suspicion of hearing loss ${ }^{4}$. Early diagnosis and adequate rehabilitation prevent the most important consequence of hearing loss: growing up with a communicative dysfunction. If the hearing dysfunction is detected late, the opportunity of intervention and rehabilitation are considerably reduced $^{5}$.

This article seeks to show the results of a research conducted between 2007 and 2008 in 151 health services providing institutions. The purpose of the research was to identify the current state of the protocols and procedures used to detect hearing loss within the first six months of the child's life; this data is not readily available in electronic files. The results of this study can contribute to the development of applied research in which we can determine the prevalence of hearing loss in the city of Cali and strengthen child protection public policies. These policies could be used by the healthcare academic community, healthcare employees, speech therapy professionals, and healthcare institutions in general.

Hearing screening has been a topic of interest for the last 40 years and its implementation has changed as technological resources have advanced. The selection process for neonates to be screened has changed during this time, given that in the past only children with risk of hearing loss, family history of deafness, low birth weight, premature, prenatal, perinatal, and postnatal infections, and children with head and neck anatomic defects were screened. Nowadays, due to worldwide research, we know that about one to three out of every 1000 newborns 
present hearing loss and have concluded that all newborns should be subject to hearing screening ${ }^{6}$. In 1994, the Joint Committee on Infant Hearing Screening $(\mathrm{JCIH})$ created and provided the guidelines for the Universal Newborn Hearing Screening (UNHS), which were re-evaluated and restated in 2007. These guidelines are summarized as follows ${ }^{5}$ :

- Every child should be entitled to a hearing screening; including children born at home, in very small towns and high-risk infants born in Intensive Care Units.

- Every detected child will be monitored during the first three months of life.

- All children with confirmed hearing loss should be intervened on within the first six months.

- Every child who passes the hearing screening, but presents risk indicators for otherauditory disorders will receive medical and auditory monitoring.

- Fluctuating hearing loss, neural conductive disorders, and central nervous system damage must be monitored.

- The child's family has the right to choose the treatment and the intervention.

On the other hand, for approximately ten years, the European AHEAD Project from the European Commission Biomedicine and Health Program promotes UNHS urging the need for hearing screening on newborns by using an effective program with standardized management guidelines ${ }^{6}$.

The arrival of better techniques for infant hearing evaluation has made the implementation of new methods and protocols possible for early detection of hearing loss. Since 1990, the effectiveness for early detection of the Automated Brainstem-Evoked Response Audiometry and the Otoacoustic Emissions (OAE) has been verified because they are noninvasive, quick, reliable, and low-cost tests ${ }^{7}$. The technological advances of diagnostic equipment have greatly contributed to a fast, reliable, and standardized implementation of UNHS in hospitals in different countries with high birth rates, before the newborns are released from hospitals.

Such is the case in Ontario, Canada, where UNHS is put into practice before the first month of the child's life. So, by the third month the complete auditory diagnosis is available ${ }^{8}$. In Latin America, we have the case of Uruguay where every child born at the Medical Corporation of Paysandu (COMEPA) has an auditory screening by using $\mathrm{OAE}$. This measure was implemented by taking into account a study done on normal newborns and others with perinatal risks, which demonstrated the importance and effectiveness of the Brainstem-Evoked Response Audiometry (BERA) and the OAE in these populations?.

The Brazilian Committee of Hearing Loss in Infancy (BCHLI) recommends the UNHS and the Hospital Universitario de São Paulo (USB) implemented it. In 2003, USB evaluated 1003 out of 1090 newborns during a four-month period. This screening was run before the children were released from the hospital (within the first 48 to 60 hours of life) by using Transient Evoked Otoacoustic Emissions.

In Mexico, according to researchers like GarcíaPedroza and Peñaloza López ${ }^{10}$, precise information is not available regarding the prevalence and incidence of hearing disorders. This situation hinders the generation of public policy and programs to assist not only newborns, but infants, teens, adults, and the elderly.

At the national level, data is available in which hearing disorders and mastoid apophysis are highlighted as the sixth cause of clinic morbidity on children one year of age and establishes the high prevalence of a variety of disorders that could affect hearing health. However, the specific diagnosis of hearing deficiency and the real statistics of people who present it are totally unknown. According to the National Institute for the Deaf in its 1998 General Activity Report, there are very few studies in the country and those existing have focused on the population over one year of age, leaving aside the early detection of auditory disorders.

The Republic of Colombia's Congressional Statue 982 of 2005 - Chapter IX, Article 44 establishes norms in favor of equal opportunities for the deaf and/or blind population. It also prescribes and 
authorizes the national government to «create» the Early Detection and Attention of Hearing Loss National Programin the Ministry of Social Protection. This Statutory Program mandates that auditory tests before the first year of life must be performed on all newborns, by using the latest scientific and technological resources available ${ }^{11}$.

Without a doubt, these are the initiatives we have been awaiting for the National Health System to implement these types of programs with the latest technological advances and qualified personnel.

\section{Sources and methods}

Between 2007 and 2008, a descriptive study was conducted in which the state of early detection programs of hearing loss in infants before the sixth month of life in the city of Cali was analyzed. This research complied with Norm 008430 of the Ministry of Health (today, the Ministry of Social Protection); the institutions surveyed signed an informed consent for their inclusion in the study. Furthermore, the identity of the participants was protected and the data gathered has only been used for research purposes.

The data was gathered through several steps:

First, the web site of the Secretary of Health of the department of Valle del Cauca was consulted to identify the Healthcare Services Providing Institutions registered in its database. There were 722 private, governmental, and / or mixed institutions by February of 2007. These institutions were included in the study's universal population. Afterwards, the data gathering instruments were designed: a) the eightquestion survey for the Health Institutions in Cali (three with dichotomous, two multiple-choice and two open questions). These questions sought to find out what institutions offered delivery room service and /or growth-development programs and /or audiology services, and b) the survey «procedures to detect hearing loss in infants before the sixth month of life in the city of Cali»; which looked to identify the procedures for hearing loss detection, the qualifications of the personnel performing the tests, and the audiology follow up and treatment provided to the children detected with hearing loss.

A pilot test was conducted at three of the institutions that offered audiology services. This test did not identify any deficiencies in shape or content. Then the eight-question survey was taken by phone and found that 151 healthcare institutions of those included in this research provided delivery room service and/or growth-development programs and/ or audiology services. Therefore, these institutions became the study sample. This information was logged onto an Excel XP spreadsheet. Lastly, the survey «procedures to detect hearing loss in infants before the sixth month of life in the city of Cali» was conducted by phone and personal interviews, with higher and lower levels of detail, respectively. The data obtained in the selected institutions for this sample was logged onto printed forms. Table 1 presents the main or dependent variable, and the independent variables classified according to the operational type of each.

The analysis unit was the institution and the main or dependent variable was the existence of early hearing loss detection programs within the first six months of life. The oral answers were re-coded into categories of two, three, and five variables. The independent variables were analyzed by calculating simple frequencies and revising each variable's absolute value. The dependent variable was analyzed by calculating the mode, the repeated answers, which was that no early detection procedures were performed.

\section{Results}

Regarding the results of the 151 healthcare institutions surveyed, it was observed that 7\% (10 institutions) provided the three services (delivery room, growth-development, and audiology); 19\% (28 institutions) had delivery room unit, but not the other two services; 79\% (120 institutions) only had the growth-development program; and 28\% (42 institutions) only provided audiology services (Table 
Table 1

Description of the variables of the study

\begin{tabular}{|c|c|c|c|}
\hline \multicolumn{4}{|c|}{ Main or dependent variable } \\
\hline 1 & $\begin{array}{l}\text { Existence of Hearing Loss Early Detection } \\
\text { Programs within the first six months of life }\end{array}$ & Categorical & $\begin{array}{l}0=\text { No } \\
1=\text { Yes }\end{array}$ \\
\hline & Indep & $\begin{array}{l}\text { Ident variable } \\
\text { Type }\end{array}$ & Operational \\
\hline 2 & $\begin{array}{l}\text { Procedures for hearing loss detection } \\
\text { Audiometry } \\
\text { Potential } \\
\text { Response audiometry }\end{array}$ & Categorical & $\begin{array}{l}1=\text { Brainstem-Evoked Response } \\
2=\text { Auditory Steady-State Evoked } \\
3=\text { Otoacoustic Emissions } \\
4=\text { Automated Brainstem-Evoked } \\
9=\text { No response }\end{array}$ \\
\hline 3 & $\begin{array}{l}\text { Professional personnel performing procedures } \\
\text { for hearing loss detection }\end{array}$ & Categorical & $\begin{array}{l}1=\text { Audiologist } \\
2=\text { Speech-language pathologist }\end{array}$ \\
\hline 4 & Admitted into audiology follow up program & Categorical & $\begin{array}{l}0=\text { No } \\
1=\text { Yes }\end{array}$ \\
\hline 5 & Phases of follow up program & Categorical & $\begin{array}{l}1 \text { = Follow up after the hearing aid } \\
2 \text { = Controls with Speech-language } \\
\text { pathologist } \\
3=\text { Remit to an audiology diagnosis, } \\
\text { hearing aid adjustment, and } \\
\text { cochlear implant } \\
4=\text { Remit to audiology diagnosis, } \\
\text { hearing aid adjustment, and cochlear } \\
\text { implant, school follow up and activities } \\
\text { with parents }\end{array}$ \\
\hline 6 & Knowledge of final hearing diagnosis & Categorical & $\begin{array}{l}0=\text { Never } \\
1=\text { Sometimes } \\
2=\text { Always }\end{array}$ \\
\hline 7 & $\begin{array}{l}\text { Existence of speech-language treatment } f \\
\text { or functional rehab of detected population }\end{array}$ & Categorical & $\begin{array}{l}0=\text { No } \\
1=\text { Yes }\end{array}$ \\
\hline 8 & Type of speech-language treatment & Categorical & $\begin{array}{l}1=\text { Adjustment of hearing aids } \\
2=\text { Cochlear implants } \\
3=\text { Auditory-verbal therapy }\end{array}$ \\
\hline 9 & Services provided by the institutions & Categorical & $\begin{array}{l}1=\text { Audiology } \\
2=\text { Growth-development program } \\
3=\text { Delivery room } \\
4=\text { three services } \\
5=\text { Audiology }+ \text { growth-development } \\
\text { program } \\
6=\text { Growth-development program }+ \\
\text { delivery room }\end{array}$ \\
\hline
\end{tabular}


Table 2

Services provided by Healthcare Institutions surveyed

\begin{tabular}{lcc}
\hline \multicolumn{1}{c}{ Services } & Institutions & $\%$ \\
\hline & 10 & 7 \\
Three services & 28 & 19 \\
$\begin{array}{l}\text { Only delivery room } \\
\text { Only growth-development } \\
\text { program }\end{array}$ & 120 & 79 \\
Only audiology & 42 & 28 \\
\hline
\end{tabular}

with a bachelor's degree was responsible for the screening.

At four of the six institutions, the patients diagnosed with hearing loss are admitted into audiology follow up programs in which the following activities are performed: one healthcare institution follows up after the patient's hearing aids are placed; another follows up every three months with speechlanguage pathologist; another refers back to an audiology diagnosis, control and reference to hearing aid adjustment and cochlear implant; and the last

Table 3

Objective procedures for hearing loss detection provided by Healthcare Institutions

Procedures for hearing loss detection

\begin{tabular}{ll} 
Auditory steady-state evoked potential, brainstem-evoked response audiometry, & \\
and otoacoustic emissions & 2 \\
Only brainstem-evoked response audiometry and otoacoustic emissions & 2 \\
Only brainstem-evoked response audiometry & 3 \\
Automated brainstem-evoked response audiometry & 1 \\
\hline
\end{tabular}

2); $95 \%$ of the healthcare institutions (144 institutions) did not provide hearing screening for infants younger than six months of age, only 4\% (6 institutions) did.

About the six institutions that performed the hearing screening in children younger than six months of age, the following was observed:

Among the objective procedures used, two of the institutions performed Auditory Steady-State Evoked Potentials, Brainstem-Evoked Response Audiometry (BERA), and Otoacoustic Emissions (OAE). Two institutions perform BERA and OAE; three only evaluate with BERA and one institution only screens with the Automated Brainstem-Evoked Response Audiometry (Table 3).

The professional personnel performing these procedures at most of these institutions (5) are speechlanguage pathologists, specialized in audiology. Only at one institution a speech-language pathologist institution, refers, controls, follow up of hearing aid treatment, cochlear implant, education and activities with parents (Table 4). At five of the six institutions, the professional assigned to a specific infant only sometimes knows the final hearing diagnosis and at one institution the professional assigned never knows this diagnosis. Five of the six institutions perform some type of hearing rehab procedure or treatment: two institutions only place hearing aids, one of them places hearing aids and performs cochlear implants, another institution adapts hearing aids, performs cochlear implants and provides auditory-verbal therapy; and another reported that it provides another type of treatment related to language screening (Table 5). Of the entire sample surveyed (151 healthcare institutions), only seven (5\%) provide hearing aid adaptation, three $(2 \%)$ perform cochlear implants, and five $(3 \%)$ provide auditory-verbal therapy. 
Table 4

Activities performed by Healthcare Institutions after detection of hearing loss

Activities after hearing loss detection

Institutions

Follow up after hearing aid adaptation

1

Follow up with speech-language pathologist every three months

1

Refer to an audiology diagnosis, control and hearing aid adaptation and cochlear implant

1

Refer to controls, follow up of hearing aid treatment and cochlear implant, education and activities with parents 1

Total 4

Table 5

Type of hearing rehab procedure or treatment for detected population Type of hearing rehab procedure or treatment Institutions

$\%$

\begin{tabular}{llc} 
Only hearing aid adaptation & 2 & 40 \\
Hearing aid adaptation + cochlear implants & 1 & 20 \\
Hearing aid adaptation + cochlear implants + auditory-verbal therapy & 1 & 20 \\
other (language screening) & 1 & 20 \\
Total & 5 & 100 \\
\hline
\end{tabular}

\section{Discussion}

Among the research results, the most interesting aspect is the low number of institutions in the city of Cali ( $4 \%$ of the healthcare institutions included) with Hearing Loss Detection Programs for infants within the first six months of life. This situation is very worrisome, considering that the communicative, affective, cognitive, and social development of children who are born with hearing loss greatly depends on early detection procedures. For this reason, the consequences of not detecting hearing loss at an early age could be devastating.

Not implementing the previously mentioned programs is alarming because there are international guidelines, like those provided by the Joint Committee on Infant Hearing (JCIH) to implement hearing loss early detection programs, which state: a hearing screening should be performed before the newborns' first month, regardless of whether they present risk factors. In addition, the hearing diagnosis should be finalized by the third month. Furthermore, the newborns not passing the initial screening and the rescreening should have a complete hearing evaluation to confirm the hearing loss within the first three months. If confirmed, they should ideally receive treatment within their first six months. And those who pass the neonatal screening, but present risk factors should have periodic hearing screening and, at the same time, the professional personnel should provide the infant's family with the proper information and assistance about the behavior and care for auditory and communicative health.

On the other hand, at the national level, the Republic of Colombia's Congressional Statute 982 of 2005 establishes norms favoring the deaf and deafblind population and authorizes the national government to create the Hearing Loss Early Detection and 
Attention Program within the jurisdiction of the Ministry of Social Protection.

Another relevant aspect of the results is that among the institutions that offer early detection programs in the city of Cali, the procedures and the personnel qualifications are very diverse; which substantiates with evidence the need to establish a program with defined and specific characteristics that could be applied in the different public and private Healthcare Services Providing Institutions at the local and national levels. Authors like Gomez ${ }^{16}$ program state that a hearing loss early detection program should have clearly defined purposes and goals, should select the sample and procedures to implement in the screening (Otoacoustic Emissions and/or Brainstem-Evoked Response Audiometry), determine the population to be screened, guarantee the infant's integration to an intervention and treatment program, and select and train the personnel who will monitor the screening results. These conditions should allow reporting $100 \%$ of sensitivity and specificity.

Establishing standards and implementing a Hearing Loss Early Detection Program within the infant's first six months of life will enable the creation of public policies in favor of the above mentioned population and the regulation of management of healthcare promoting entities regarding intervention on the population diagnosed with hearing loss.

\section{Conclusions}

Based on this study, we can conclude that the city of Cali does not have structured Universal Neonatal Hearing Screenings; even though six private institutions have implemented some procedures for hearing loss detection and diagnosis during the infant's first six months. The lack of theoretical knowledge programs is evident, along with lack of application of specific techniques and equipment and management procedures established in the universal evaluation system, which would allow for early hearing loss detection in the city of Cali.
No public healthcare promoting entities in Cali offers Hearing Loss Early Detection Programs. Only some private healthcare services providing institutions have some early detection and diagnostic procedures during the first six months of the child's life. These procedures are isolated efforts, which are not part of complete programs with guarantees of universal coverage, follow up, and intervention procedures.

Lack of standardized Universal Neonatal Hearing Screening Programs in our country has resulted in a sub-diagnosis of genetic hearing disorders. This substantiates the need to implement strategies to train the institutions, associations, and healthcare governmental bodies.

Despite the Congressional Statute 982 in 2005 ordering the creation of Hearing Loss Early Detection Programs, the Universal Neonatal Screening Programs have not been structured in the city of Cali. The scientific community related to audiology must provide an effective and efficient instrument, with clear guidelines and total coverage that would meet the needs of the population in the city of Cali and allows hearing loss early detection becoming a reality in the city.

Conflict of interest. None of the authors has conflicts of interest related to this study.

\section{References}

1. Yoshinaga-Itano C, Sedey AL, Coulter DK, Mehl AL. Language of early and late identified children with hearing loss. Pediatrics. 1998; 102: 1161-71.

2. Brigard de Pardo ME, Gómez C, González de Barreto H, Pastoriza S, Rángel P, Restrepo C, Villegas B. Detección temprana de pérdidas auditivas un deber pospuesto. Acta Otorrinolaringol Cir Cabez. A Cuello. 2002; 30: 9-18.

3. Culpepper, B. Starting a screening program. Hearing J. 2000; 51: 28-32.

4. Joint Committee on Infant Hearing. Principles and guidelines for early bearing detection and intervention programs. Washington, DC: Joint Committee on Infant Hearing; 2007. Available in: http://www.asha.com

5. Marcoux A. Modelos de tamizajes auditivos. En: Actualización internacional en audiología pediátrica. Cali, febrero 15-17, 2007.

6. Peña J, Dal Monte E, Della S. Detección universal de 
hipoacusia en recién nacidos y lactantes. Fono.com Magazín. Asociación Colombiana de Fonoaudiología y TL. 1: 10-11.

7. Durante AS, Carvallo RMM, Costa MTZ, Ianciarullo MA, Voegels RL, Takahashi GM, Soares AVN, Spir EG. A implementação de programa de triagem auditiva neonatal universal em um hospital universitário brasileiro. Pediatria. 2004; 26: 78-84.

8. García-Pedroza F, Peñaloza Y. ¿Son los trastornos auditivos un problema de salud pública en México? Rev MexNeurocir. 2004; 48: 20-9.
9. Ministerio de Educación Nacional, Instituto Nacional para Sordos (INSOR). La salud en Colombia: 10 años de información. Bogotá: INSOR; 2003.

10. Ramírez R. Conocer al niño sordo. Ciencias de la educación preescolar y especial. Madrid: General Pardiñas; 2005.

11. Gómez O. Pautas para el tamizaje auditivo. En: Obando F. Audiología básica. Bogotá: Universidad Nacional de Colombia; 2006. p. 275 